\title{
Hormones and metabolic adaptation in the newborn
}

\author{
By J. M. BASSETT, University of Oxford, Growth and Development Unit, University Field \\ Laboratory, Wytham, Oxford OX2 8QJ
}

Birth, an inescapable event in the development of placental mammals, marks a boundary between total dependence on the mother for sustenance and the beginnings of independent existence for the newborn infant. The timing of birth and extent of the infant's independence vary enormously amongst species, so it is very difficult to generalize about events occurring at this time. A role for the fetus in the initiation of its own birth is now clearly recognized in many species, but the timing of birth relates as much to the behavioural pattern of the mother and her ability to provide a birthplace secure from predators and protected from the worst vicissitudes of the environment, as it does to the physiological development of the infant. Solutions to the problems of protecting the newborn from the environment and predation are almost as diverse as the species themselves, so we should expect to find great variation in the ways metabolism adapts to the new independence of post-natal life.

The variable timing of delivery in relation to physiological development among species dictates that the adaptive solutions will vary. Nevertheless, many of the changes, perforce, occur in newborn infants of virtually all species. Many have no direct relevance for the present discussion, others, however, have implications for metabolism and the nutritional welfare of the newborn. Expansion of the lungs and establishment of satisfactory pulmonary ventilation are of crucial relevance to the support of oxidative metabolism, through provision of oxygen and removal of carbon dioxide, as are the reorganization of the circulatory system and redistribution of cardiac output after severance of the umbilical cord. Immaturity or abnormalities in adaptation of either of these systems after birth may result in major complications for regulation of metabolism and survival. However, the adaptive mechanisms of greatest relevance to the present discussion are those relating to the regulation of homeothermy and metabolism itself.

Before birth, thermoregulation is principally a question of adequate removal of heat generated by metabolic activity in the fetus and its placenta. The evidence indicates that this is achieved predominantly through heat exchange between fetal and maternal blood circulating within the placenta, though there is some evidence that the fetal lamb is already capable of participating in thermoregulation through control of skin blood flow (Kawamura et al. 1986). Following birth, however, maintenance of body temperature necessitates active regulation of heat production and conservation by the infant, either through alteration of cardiac output, blood flow distribution and neurohumoral regulation of tissue metabolism, or by behavioural adaptation to minimize heat loss to the environment. The mechanisms involved and their regulation have been the subject of detailed review (Alexander, 1979). Few infants are born into a thermal environment where they are immediately within their thermoneutral zone. Heat conservation and additional heat production, therefore, become essential to survival at this time, despite the coincident cessation of parenteral nutrition and commencement of the infant's first fast. Consumption of energy for the sole purpose of heat generation to maintain homeothermy, whether through shivering or through non-shivering thermogenesis in brown fat, therefore, becomes an important factor influencing the relationship between energy reserves and post-natal survival till the first feed. 
In all probability it is the neural and endocrine responses to the thermal insult, as much as to the trauma of birth itself, which prime and coordinate the subsequent changes in metabolic activity, so vital to survival before the initiation of enteral nutrition. The observations of Kawamura et al. (1986) and Gunn et al. (1986) on the effects of cooling fetal lambs in utero provide a valuable insight into the range of cardiovascular, endocrine and metabolic changes consequent on such a thermal stimulus, independent of the other components of the birth process, and give an indication of the important contribution which sympathoadrenal mechanisms make to these changes. Whatever the actual mechanisms used to support homeothermy in this period, their success will depend on the continued provision of oxidizable substrates and maturity of mechanisms regulating their use. The prenatal accumulation of reserves of readily mobilizable substrates and rapid establishment of oral feeding are, therefore, important determinants of adaptation to post-natal life and subsequent survival.

\section{Substraie reserves and their availability}

Despite the variation among species in the physiological maturity of their infants at birth, substantial quantities of glycogen are accumulated within fetal tissues before this event, and serve to support metabolism during the first hours of post-natal life (Shelley, 1961). Prenatal lipid storage, whether in white or brown adipose tissue (Cannon \& Nedergaard, 1982; Cryer, 1982), is more variable amongst species, reflecting differences in physiological maturity and placental permeability, as well as the nature and harshness of the post-natal environment. The hormonal requirements for this prenatal substrate accumulation are now well known (Barnes et al. 1977; Bassett \& Fletcher, 1982; Girard \& Ferre, 1982; Jones \& Rolph, 1985). While many hormones are essential in permissive roles, it is clear that the main determinants are the glucocorticoids and the dominance of anabolic metabolism by insulin at this time, although it is evident that substantial accumulation of hepatic glycogen also may occur in severely growth retarded fetuses where insulin levels are far lower (Lafeber et al. 1984).

Of the possible fuels for fetal oxidative metabolism and substrates for prenatal energy storage, glucose has received most detailed study. Extensive investigations attest to its importance as the principal fuel for fetal metabolism (Battaglia \& Meschia, 1978), and this view has been confirmed by quantitative measurements of uterine and umbilical glucose uptake as well as by kinetic studies utilizing labelled tracers, although it is clear from measurements of radioactive $\mathrm{CO}_{2}$ production from labelled glucose that it is by no means the only contributor to oxidative metabolism in the fetal lamb (Setchell $e t$ al. 1972). In addition, although early investigations showed that glucose was readily incorporated into glycogen and into both structural and storage lipids in fetal lambs (Scott et al. 1967; Setchell et al. 1972), more recent quantitative studies of glucose utilization have, as pointed out by Jones \& Rolph (1985), done little to delineate further how glucose utilization within the fetus and its placenta is partitioned amongst metabolic pathways and tissues, or the means by which this is regulated.

Studies of pancreatectomized lambs (Fowden \& Comline, 1984; Fowden et al. 1986) and many studies on the effects of insulin administration to fetuses are indicative of a very important role for this hormone in regulating fetal glucose metabolism. However, recent investigations (Bloch et al. 1988; Hay et al. 1988) do indicate that glucose concentration and cellular uptake by insulin-insensitive pathways make equal or greater contributions to the regulation of fetal glucose utilization than utilization by insulinsensitive pathways. This lesser dependence of glucose metabolism on insulin may partly explain how glycogen accumulation still occurs in growth-retarded fetuses where plasma insulin levels are very low (Lafeber et al. 1984). Further, the observations of Hay \& 
Meznarich (1986) show that insulin, while stimulating cellular glucose uptake, apparently does not alter the proportions of glucose oxidized or utilized by other pathways in the fetus, a situation quite different from that in the adult, suggesting that we still know little about the detailed regulation of fetal tissue glucose metabolism at this time, let alone that of any other metabolic substrate.

The consequences for regulation of energy metabolism during the early post-natal period of different prenatal energy storage strategies have recently been highlighted by the elegant comparative analysis of relationships between post-natal survival and energy reserves at birth in lambs, piglets and newborn babies by Mellor \& Cockburn (1986). Utilizing existing information about glycogen and lipid deposition in these species at birth, and knowledge of rates of energy utilization under defined temperature regimens, their analysis shows clearly the extent to which post-natal survival in these three contrasting species is influenced by the amount and nature of prenatal energy storage, as well as by the thermal stresses to which the newborns are subjected. Strategies for maintenance of homeothermy vary greatly among the three species, depending on relative amounts of glycogen (especially hepatic glycogen), brown fat and mobilizable lipid available at the time of birth. In the piglet, born with little thermal insulation, little available hepatic glycogen and trivial lipid reserves, survival is limited by the available lipid. Shivering, utilizing muscle glycogen, makes a major contribution to heat production, and establishment of enteral nutrition within the first few hours of life is essential for survival. The human baby, by contrast, has substantial lipid and glycogen reserves, and is far less dependent on early establishment of enteral feeding, so the slow onset of lactation in the mother is less critical for survival. The lamb lies somewhere between these two species, the substrate limiting its survival being determined both by the adequacy of prenatal nutrition and by the severity of the environmental insult to which it is subjected, though this, of course, is generally more severe than that experienced by the other species. However, while such an analysis gives valuable insights into the limitations imposed on perinatal metabolism by substrate supply before the onset of enteral nutrition, it gives, as the authors acknowledge, little clue to the complex neural and humoral changes which regulate utilization of the available substrates to maintain metabolic homeostasis, or to limitations on the analysis imposed by specific tissue substrate requirements.

Despite the essential requirement to maintain thermoneutrality, maintenance of normoglycaemia may itself be of over-riding significance, because of the need to maintain the supply of readily oxidizable substrate to the neural tissues coordinating metabolic activity throughout the body. Bougnères (1987) has observed that measured rates of glucose utilization in newborn infants remain far higher than those of adults, even after allowance for the greater proportion of brain tissue, and despite the low insulin levels usually observed at this time. Even in the human baby, glucose production from hepatic glycogen stores (the only reserve of glucose directly available to the newborn for the support of the blood level) can provide about one-third of the glucose required to maintain these high rates of utilization during the first $24 \mathrm{~h}$ of post-natal life. With the trivial amount of glucose likely to be derived from enteral nutrition during this time in the human infant, rapid post-natal development of gluconeogenesis as a major source of glucose is vital to survival, as it is in the other species with smaller substrate reserves at birth (Girard \& Ferre, 1982). The frequency with which hypoglycaemia occurs in otherwise healthy newborn infants, as well as in macrosomic infants of diabetic mothers, and its relation to inappropriate hyperinsulinaemia in these infants (AynsleyGreen, 1982; Knip et al. 1983), highlights the delicate balance in metabolic regulation which exists at this time. 
The studies of Girard and associates have defined in considerable detail the hepatic enzymic and regulatory hormonal changes associated with the onset of gluconeogenesis in the newborn (Girard \& Ferre, 1982), and highlight the significance of a dramatic change in the insulin:glucagon ratio from dominance by insulin during fetal life to dominance by glucagon after birth. Their studies have also demonstrated the necessity for rapid activation of pathways for mobilization of free fatty acids from adipose tissue, or uptake from the gut after establishment of enteral feeding, and for subsequent fatty acid oxidation within hepatocytes if gluconeogenesis is to be maximally stimulated (Ferre et al. 1985; Pegorier et al. 1985, 1987). Promotion of increased mobilization and tissue oxidation of free fatty acids (FFA) also appears able to contribute to perinatal glucose homeostasis by reducing peripheral utilization of glucose, possibly by as much as $30 \%$ (Ferre et al. 1985). Indeed, low rates of FFA turnover before birth could be a key factor maintaining the high rate of glucose oxidation in many fetal tissues, so increased fat oxidation is clearly an important component of the metabolic adjustments necessary after birth. Reinforcement of this view comes from their recent finding that a threefold decrease in the insulin:glucagon ratio and a substantial increase in fatty acid oxidation are associated with initiation of gluconeogenesis in the post-mature rabbit fetus (Herbin et al. 1988). While the importance of the pancreatic hormone changes has been emphasized by Girard \& Ferre (1982), it must be appreciated that these changes are themselves largely determined by the dramatic changes in function of the sympathoadrenal system at this time.

\section{The role of the sympathoadrenal system}

Changes in the function of the sympathoadrenal system, associated with the onset of labour, delivery and the initial stages of neonatal adaptation, must rank among the most spectacular of the adaptive responses to birth, with plasma catecholamine concentrations in the newborn during normal delivery greatly exceeding concentrations encountered in the mother during labour, or in other adults during grossly pharmacological situations (Jones, 1980; Hagnevik et al. 1984; Lagercrantz \& Slotkin, 1986). Sympathetic innervation of the adrenal medulla probably plays an important part in this response in the lamb (Comline \& Silver, 1961; Jones, 1980), but in many species, possibly including man, innervation of the adrenal medulla is incomplete at birth so the secretory response may be more dependent on non-neurogenic stimuli such as hypoxia (Slotkin \& Seidler, 1988) and may, therefore, be less precisely regulated.

The marked elevation of circulating catecholamine concentrations at this time is thought to assist the neonate in adapting metabolic, cardiovascular and respiratory systems to the demands of postnatal life (Jones, 1980; Sperling et al. 1984). Their significance for the maintenance of metabolic homeostasis during the perinatal period, through their regulation of pancreatic-islet-hormone release and adipocyte metabolism have been particularly emphasized (Milner \& De Gasparo, 1981; Sperling, 1982; Sperling et al. 1984). Observations on the responses of fetal and newborn lambs administered catecholamines are consistent with this view, infusion of adrenaline leading to cardiovascular changes comparable to those observed during hypoxaemia in utero and in the immediate post-natal period (Jones, 1980). Hormonal changes observed include inhibited insulin and growth hormone release, but increased glucagon and ACTH release (Bassett \& Alexander, 1971; Jones, 1980; Sperling et al. 1984). Increased plasma glucose, lactate and FFA levels indicative of stimulated hepatic glycogenolysis and adipose tissue lipolysis have also been observed. Studies with adrenergic blocking agents (Sperling et al. 1980) suggest that tonic catecholamine release may already be limiting insulin secretory responsiveness prenatally. Observations in our own laboratory 
(Bassett, 1985) show that the fetal lamb pancreas is capable of responding to catecholamines by mid-gestation, and even in rats, where innervation of the adrenal medulla does not occur until after birth, functional sympathetic innervation is present in the pancreas before delivery (Milner \& De Gasparo, 1981). Non-shivering thermogenesis in brown adipose tissue is of course also dependent on noradrenaline released at sympathetic nerve terminals within the tissue (Cannon \& Nedergaard, 1982).

Recent observations on the effects of cooling fetal lambs in utero provide support for these views (Gluckman et al. 1983; Gunn et al. 1985, 1986; Kawamura et al. 1986), as the procedure provokes increases in circulating catecholamine concentrations comparable to those observed at delivery in full-term lambs (Jones, 1980; Padbury et al. 1985), and leads to many of the cardiovascular and metabolic changes considered important for metabolic homeostasis in the neonate. However, while both Gunn et al. (1985) and Kawamura et al. (1986) provide suggestive evidence for increased $\mathrm{O}_{2}$ consumption during fetal cooling, the site of this increased utilization is more equivocal. Electromyograms are indicative of shivering, but muscle blood flow is not increased. On the other hand, although blood flow to brown adipose tissue is greatly increased, plasma FFA levels do not change.

Additional evidence that the mobilization of FFA by catecholamines may be refractory to stimulation in utero was also provided by Padbury et al. (1985), who showed that cord cutting in preterm lambs, though associated with greater sympathoadrenal responses than those seen in term lambs, resulted in blunted responses in FFA, glucose, heart rate and blood pressure. Down regulation of adrenoceptors could provide an alternative explanation to immaturity of the responses, for Jones et al. $(1987,1988)$ have shown that chemical sympathectomy of fetal lambs results in supersensitivity to catecholamines. However, Fisher et al. (1977) also showed that changes in plasma FFA in lambs following delivery, like those in tri-iodothyronine $\left(\mathrm{T}_{3}\right)$, were associated with cord cutting rather than with the other sequelae of delivery, but the mechanism by which the placenta appears to inhibit fatty acid mobilization remains unknown. These investigations also highlighted another aspect of the endocrine adaptations occurring after delivery in which catecholamines are clearly implicated. Despite development of the hypothalamo-pituitary-thyroid axis well before term, and clear evidence for important roles of thyroid hormones in prenatal development of the lamb and human baby, plasma $\mathrm{T}_{3}$ levels remain very low until delivery (Fisher et al. 1977). After birth thyrotrophin and thyroxine $\left(\mathrm{T}_{4}\right)$ levels rise in response to the thermoregulatory stimulus; $\mathrm{T}_{3}$ levels, however, increase far more dramatically. Explanations for this rise have been sought in increased deiodination of $T_{4}$ by liver and other peripheral tissue. However, investigations by Silva \& Larsen (1983) suggest a more plausible explanation. Stimulation of brown adipose tissue by noradrenaline leads not only to increased lipolysis but also to activation of a type II $5^{\prime}$-deiodinase (EC 3.8.1.4) within the adipocytes and increased conversion of $T_{4}$ to $T_{3}$. Binding of $T_{3}$ to nuclear receptors within the adipocyte leads to increased synthesis of thermogenin and thus to increased efficiency of the cell as a heat producer (Bianco \& Silva, 1987). At the same time the deiodinase reaction also contributes $T_{3}$ to the plasma pool. Other investigations have also demonstrated the essential requirement for thyroid hormones for catecholamines to stimulate a normal thermogenic response in brown adipose tissue of newborn lambs (Klein et al. 1984; Polk et al. 1987). Interactions between the catecholamines and thyroid hormones may, therefore, be as significant as those between catecholamines and pancreatic hormones in determining the metabolic responses of newborns adapting to their new environment.

In assessing the significance of the endocrine responses after birth for metabolic homeostasis in the neonate before initiation of enteral nutrition it may be valuable to 
compare this situation with other situations, such as exercise or cold exposure, where sympathoadrenal activity is increased. Careful investigations by Cryer and associates of the mechanisms counteracting hypoglycaemia in these situations have led to the concept of redundant glucoregulatory systems which can contribute to glucoregulation if the principal regulatory system is disabled. Their studies (Hoelzer et al. 1986) indicate that the hierarchy during exercise begins with sympathocromaffin activation. This plays a primary role in limiting glucose utilization as well as stimulating its production. Pancreatic-islet-hormone changes only become critical when catecholamine action is deficient. In the neonate, where sympathetic innervation of both liver and pancreatic islets may be immature, the hierarchy may differ, and may include other hormones such as $T_{3}$. Nevertheless, this concept may still have value in emphasizing the complementary roles of sympathoadrenal and pancreatic islet hormones in regulating carbohydrate homeostasis at this time, so may be worthy of more careful investigation. Ultimately, however, the success of these endocrine and metabolic adaptive changes must be judged by their ability to preserve metabolic homeostasis and integrative neural function till the infant has successfully sought a supply of colostrum and initiated enteral nutrition.

\section{REFERENCES}

Alexander, G. (1979). International Review of Physiology 20, 43-155.

Aynsley-Green, A. (1982). Clinics in Endocrinology and Metabolism 11, 159-194.

Barnes, R. J., Fowden, A. L., Silver, M. \& Comline, R. S. (1977). Annales de Recherches Veterinaires 8, 374-378.

Bassett, J. M. (1985). In The Physiological Development of the Fetus and Newborn, pp. 123-133 [C. T. Jones and P. W. Nathanielsz, editors]. London: Academic Press.

Bassett, J. M. \& Alexander, G. (1971). Biology of the Neonate 17, 112-125.

Bassett, J. M. \& Fletcher, J. M. (1982). In Biochemical Development of the Fetus and Neonate, pp. 393-423 [C. T. Jones, editor]. Amsterdam: Elsevier Biomedical Press.

Battaglia, F. C. \& Meschia, G. (1978). Physiological Reviews 58, 499-527.

Bianco, A. C. \& Silva, J. E. (1987). American Journal of Physiology 253, E255-E263.

Bloch, C. A., Menon, R. K. \& Sperling, M. A. (1988). American Journal of Physiology 255, E87-E93.

Bougnères, P. F. (1987). Biology of the Neonate 52, Suppl. 1, 87-96.

Cannon, B. \& Nedergaard, J. (1982). In Biochemical Development of the Fetus and Neonate, pp. 697-730 [C. T. Jones, editor]. Amsterdam: Elsevier Biomedical Press.

Comline, R. S. \& Silver, M. (1961). Journal of Physiology 156, 424-444.

Cryer, A. (1982). In Biochemical Development of the Fetus and Neonate, pp. 731-757 [C. T. Jones, editor]. Amsterdam: Elsevier Biomedical Press.

Ferre, P., Turlan, P. \& Girard, J. (1985). Journal of Developmental Physiology 7, 37-46.

Fisher, D. A., Dussault, J. H., Sack, J. \& Chopra, I. J. (1977). Recent Progress in Hormone Research 33, 59-107.

Fowden, A. L. \& Comline, R. S. (1984). Quarterly Journal of Experimental Physiology 69, 319-330.

Fowden, A. L., Silver, M. \& Comline, R. S. (1986). Quarterly Journal of Experimental Physiology 71, 67-78.

Girard, J. \& Ferre, P. (1982). In Biochemical Development of the Fetus and Neonate, pp. 517-551 [C. T. Jones, editor]. Amsterdam: Elsevier Biomedical Press.

Gluckman, P. D., Gunn, T. R. \& Johnston, B. M. (1983). Journal of Physiology 343, 495-506.

Gunn, T. R., Butler, J. \& Gluckman, P. D. (1986). Journal of Developmental Physiology 8, 55-66.

Gunn, T. R., Johnston, B. M., Iwamoto, H. S., Fraser, M., Nicholls, M. G. \& Gluckman, P. D. (1985). Journal of Developmental Physiology 7, 241-249.

Hay, W. W. \& Meznarich, H. K. (1986). Quarterly Journal of Experimental Physiology 71, 689-698.

Hay, W. W., Meznarich, H. K., DiGiacomo, J. E., Hirst, K. \& Zerbe, G. (1988). Pediatric Research 23, 381-387.

Hagnevik, K., Faxelius, G., Irestedt, L., Lagercrantz, H., Lundell, B. \& Persson, B. (1984). Acta Paediatrica Scandinavica 73, 602-609. 
Herbin, C., Duee, P. H., Pegorier, J. P., Blade, C., Kohl, C. \& Girard, J. (1988). Pediatric Research 23, 224-228.

Hoelzer, D. R., Dalsky, G. P., Clutter, W. E., Shah, S. D., Holloszy, J. O. \& Cryer, P. E. (1986). Journal of Clinical Investigation $77,212-221$.

Jones, C. T. (1980). In Biogenic Amines in Development, pp. 63-86 [H. Parvez and S. Parvez, editors]. Amsterdam: Elsevier/North Holland.

Jones, C. T., Roebuck, M. M., Walker, D. W. \& Johnston, B. M. (1988). Journal of Developmental Physiology 10, 17-36.

Jones, C. T., Roebuck, M. M., Walker, D. W., Lagercrantz, H. \& Johnston, B. M. (1987). Journal of Developmental Physiology 9, 347-367.

Jones, C. T. \& Rolph, T. P. (1985). Physiological Reviews 65, 357-430.

Kawamura, T., Gilbert, R. D. \& Power, G. G. (1986). Journal of Developmental Physiology 11, 11-21.

Klein, A. H., Reviczky, A. \& Padbury, J. F. (1984). Endocrinology 114, 1065-1069.

Knip, M., Lautala, P., Leppaluoto, J., Akerblom, H. K. \& Kouvalainen, K. (1983). Journal of Pediatrics 103, 603-611.

Lafeber, H. N., Rolph, T. P. \& Jones, C. T. (1984). Journal of Developmental Physiology 6, 441-459.

Lagercrantz, H. \& Slotkin, T. A. (1986). Scientific American 254, 100-107.

Mellor, D. J. \& Cockburn, F. (1986). Quarterly Joumal of Experimental Physiology 71, 361-379.

Milner, R. D. G. \& De Gasparo, M. (1981). In Development of the Autonomic Nervous System. Ciba Foundation Symposium no. 83, pp. 291-309 [G. Burnstock, editor]. London: Pitman Medical.

Padbury, J. F., Polk, D. H., Newnham, J. P. \& Lam, R. W. (1985). American Journal of Physiology 248, E443-E449.

Pegorier, J. P., Duee, P. H. \& Girard, J. R. (1987). Biology of the Neonate 51, 31-39.

Pegorier, J. P., Simoes-Nunes, C., Duee, P. H., Peret, J. \& Girard, J. (1985). American Joumal of Physiology 249, E268-E275.

Polk, D. H., Callegari, C. G., Newnham, J., Padbury, J. F., Reviczky, A., Fisher, D. A. \& Klein, A. H. (1987). Pediatric Research 21, 453-457.

Scott, T. W., Setchell, B. P. \& Bassett, J. M. (1967). Biochemical Journal 104, 1040-1047.

Setchell, B. P., Bassett, J. M., Hinks, N. T. \& Graham, N. McC. (1972). Quarterly Joumal of Experimental Physiology 57, 257-266.

Shelley, H. J. (1961). British Medical Bulletin 17, 137-143.

Silva, J. E. \& Larsen, P. R. (1983). Nature 305, 712-713.

Slotkin, T. A. \& Seidler, F. J. (1988). Journal of Developmental Physiology 10, 1-16.

Sperling, M. A. (1982). Monographs in Paediatrics 16, 39-58.

Sperling, M. A., Christensen, S., Ganguli, S. \& Anand, R. (1980). Pediatric Research 14, $203-208$.

Sperling, M. A., Ganguli, S., Leslie, N. \& Landt, K. (1984). American Journal of Physiology 247, E69-E74. 